\title{
Projeto piloto: aproveitamento de retraços têxteis para 0 artesanato conceitual
}

\author{
Pilot project: exploitation of textile snip for conceptual handicraft
}

\author{
LAGO, Lílian; Universidade Estadual de Londrina \\ lago.lilian@gmail.com \\ CAVALCANTE, Ana Luísa Boavista Lustosa; Mestre; Universidade Estadual de Londrina \\ anaboavista@uel.br \\ SAMPAIO, Cláudio Pereira de; Mestre; Universidade Estadual de Londrina \\ qddesign@hotmail.com
}

\begin{abstract}
Resumo
Este trabalho apresenta um projeto piloto que interliga empresas confeccionistas e um grupo artesanal de geração de renda, fazendo com que os retraços têxteis da indústria sejam insumos produtivos do trabalho artesanal. Para tal foi utilizado o método de pesquisa-ação, que contempla o levantamento bibliográfico e a pesquisa social. O projeto demonstra a viabilidade desta conexão baseada no metabolismo industrial e a importância do design para se criar a cultura de inovação e trazer competitividade de mercado ao empreendimento. A realização deste projeto piloto propõe um novo método de trabalho a ser replicado.
\end{abstract}

Palavras-chave: Sustentabilidade; Retraços Têxteis; Artesanato conceitual

\begin{abstract}
This paper presents a pilot project that links clothing industries and a craft group for income generation, to industry retrace textile become productive inputs of craft work. To this end we used the method of action research, which includes the bibliography and social research. The project demonstrates the feasibility of this connection based on the industrial metabolism and the importance of design to create a culture of innovation and bring to the enterprise market competitiveness. The completion of this pilot project proposes a new method of work to be replicated.
\end{abstract}

Keywords: Sustainability; Textile snip; Conceptual handicraft

\section{Introdução}

$\mathrm{Na}$ produção industrial, os resíduos dos processos, como os retraços têxteis, geralmente são descartados, transformando-se em lixo e causando impacto ambiental. Para Kazazian (2005), aproveitar este resíduo descartado é uma das proposições do ecodesign, que ao analisar o ciclo de vida do produto, agrega função aos resíduos, que se tornam 
insumo de uma nova produção, reduzindo os impactos ao meio ambiente.

Silva $(2009$, p. 4) afirma que

$\mathrm{O}$ artesanato considera as quatro dimensões proposta pela sustentabilidade: a social, ao gerar trabalho e renda a pessoas desfavorecidas economicamente; a ambiental, ao possibilitar a utilização de resíduos descartados precocemente e de materiais menos nocivos; a econômica, por ser voltado para fins de comercialização com base na identificação de uma demanda; e a cultural, ao respeitar a individualidade do artesão e das características locais da comunidade a qual pertence e preservar a cultura local.

Alinhando design, sustentabilidade e artesanato, Cavalcante e Pereira (2007, p. 9) dissertam que

[...] o Design, atividade profissional que desenvolve produtos diante as necessidades humanas, tem uma grande responsabilidade em construir conhecimentos junto a esses microempreendimentos sociais, solidários e sustentáveis, contribuindo para a melhoria da qualidade de vida e acima de tudo para a preservação do planeta.

Logo, o projeto de pesquisa "Indicadores de design para o desenvolvimento sustentável - formação de rede interativa de reciclagem e reaproveitamento na produção artesanal de grupos de geração de trabalho e renda" ${ }^{1}$, em parceria com o grupo Empreender do Instituto Milenia, realizou um projeto piloto, cujo objetivo é produzir uma nova linha de artesanato conceitual que tenha como insumos, os retraços têxteis descartados pelas confecções da região de Londrina.

O projeto seguirá as seguintes etapas:

1) Sensibilização: design e mercado

2) Caracterização dos resíduos de tecido e processos

3) Geração de ideias

4) Implementação dos produtos

5) Resultados

A contrapartida ao trabalho do design para com o grupo será a oficina de papel artesanal que as artesãs irão dar para os alunos e professores do design, uma forma de retribuir o trabalho e principalmente, trocar conhecimentos.

Para demonstrar melhor o funcionamento do projeto piloto, utilizou-se como referência o diagrama de Cavalcante et al. (2008), como pode ser visto a seguir.

\footnotetext{
1 A partir daqui tratado como IDDS.
} 


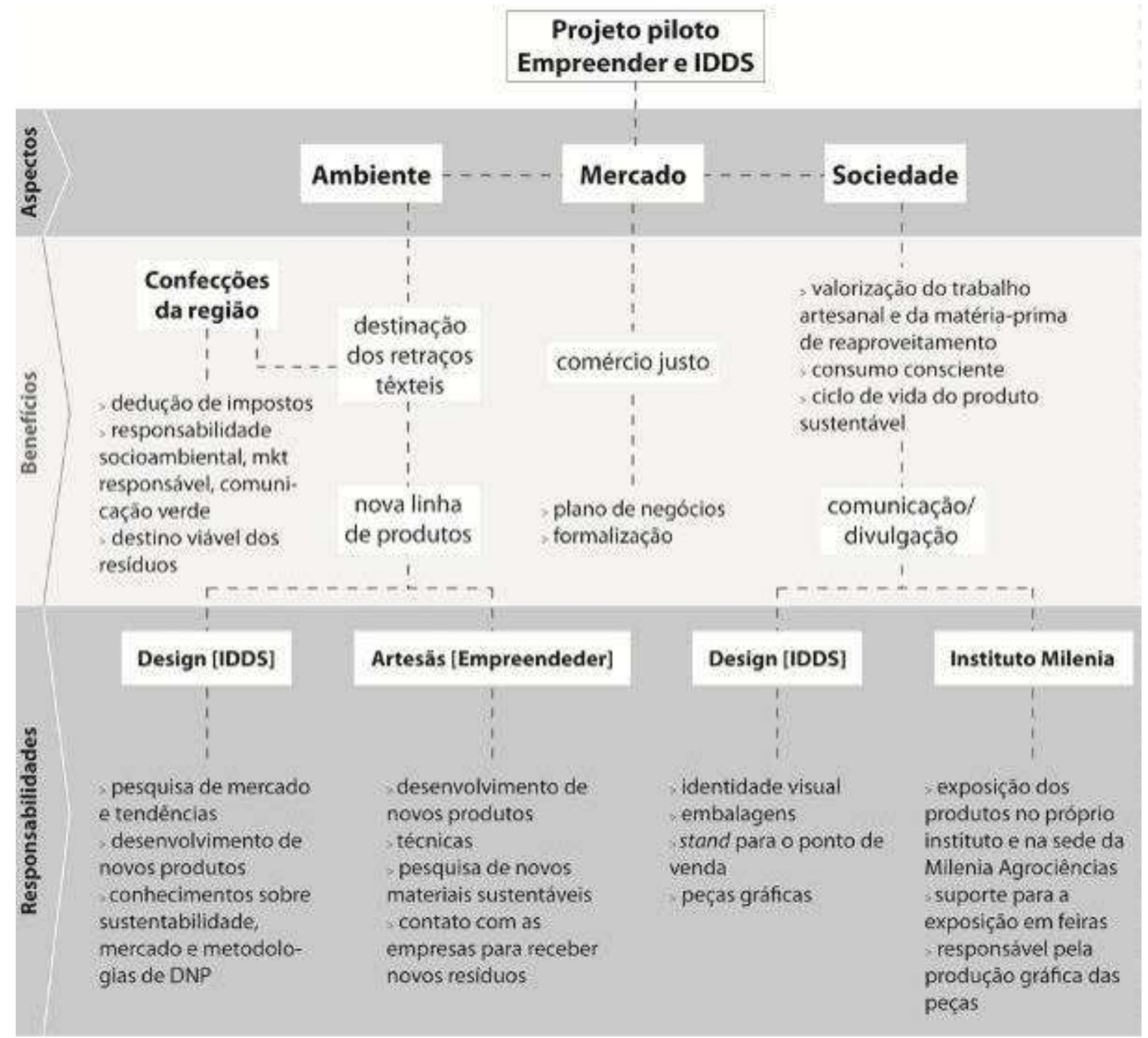

Figura 1 - Diagrama sobre o projeto piloto entre Grupo Empreender e IDDS Fonte: Lago (2010)

Este projeto piloto, além de estar contido nas atividades do projeto de pesquisa IDDS, também faz parte do trabalho de conclusão de curso da autora ${ }^{2}$, que desenvolveu um modelo produtivo para integrar indústria do vestuário, grupos artesanais e design por meio do aproveitamento de retraços têxteis.

2 LAGO, Lílian. Modelo produtivo sustentável: potencialidades do aproveitamento de retraços têxteis na região de Londrina. 2010. 150 p. Trabalho de Conclusão de Curso (Graduação em Design Gráfico) Universidade Estadual de Londrina, Londrina. 


\title{
Revisão de Literatura
}

\section{O design, a sustentabilidade e o artesanato}

Segundo Ullmann (2007, p. 1):

\begin{abstract}
A realidade sócio-ambiental e as últimas transformações sociais e econômicas no Brasil constatam a falta de equilíbrio e a injustiça em que vive o povo de modo geral. Nesse contexto, o design apresenta-se como um fator estratégico de mercado e como um diferencial decisivo para artesãos e para comunidades com interesse no nicho do comércio ético e solidário, seja nacional, seja internacional. O design tem um importante papel no planejamento de um futuro responsável e comprometido com o meio ambiente e com a sociedade, caso suas ambições se alinhem com conceitos sustentáveis. O design surge, então, como uma ferramenta indispensável para melhorar o propósito do produto, a sua estratégia de venda e o sistema em que se insere. Assim, considerar não só aspectos econômicos e estéticos, mas também ambientais e sociais, de cada produto é o que podemos elencar como características diferenciais do design sustentável.
\end{abstract}

Martins e Silva (2009, p. 9) também apontam as potencialidades e deveres do design diante da realidade social.

O designer de hoje olha para o mercado e para o que está logo ao seu lado na periferia. O feio incomoda. Prefere olhar para si e em um processo de autoreverenciação cria produtos e atividades para os outros designers. É preciso escapar desta zona de conforto e se voltar para os outros $90 \%$. Sem isso não se pode falar em sustentabilidade. Enquanto houver pobreza não haverá sustentabilidade. [...] É preciso urgentemente mudar de estratégia e criar novas soluções. Projetos que envolvam grupos em situação de pobreza exigem a aplicação de estratégias de sustentabilidade inovadoras.

São vários os exemplos de união entre o design e o artesanato que tem despontado. Entre eles, pode-se destacar "O Imaginário Pernambucano", um projeto de extensão da Universidade Federal de Pernambuco que busca valorizar a identidade das comunidades artesanais, disseminar o associativismo e a permitir aos artesãos viver desta renda de forma sustentável. O projeto recebeu em 2008 o troféu IDEA/Brasil, a versão brasileira de um dos mais importantes prêmios de design do mundo, na categoria melhor projeto de pesquisa.

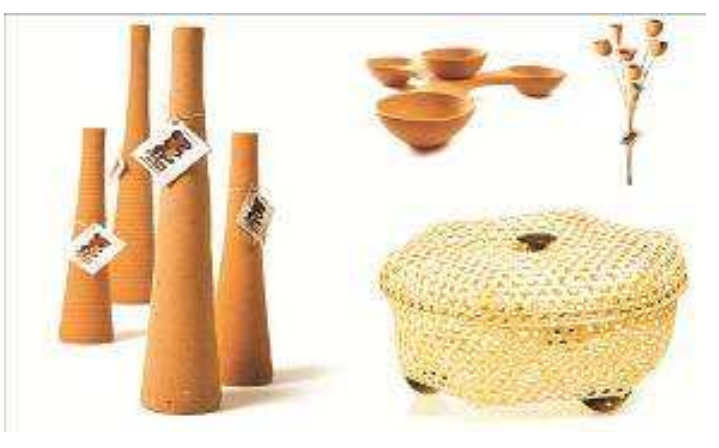

Figura 2 - Produtos d'O Imaginário Pernambucano Fonte: O IMAGINÁRIO... (2008) 


\section{O Artesanato}

O Programa SEBRAE Artesanato, do SEBRAE (2004), apresentou as características e diferenças do artesanato brasileiro que permitem classificá-lo em categorias de diferentes valores culturais.

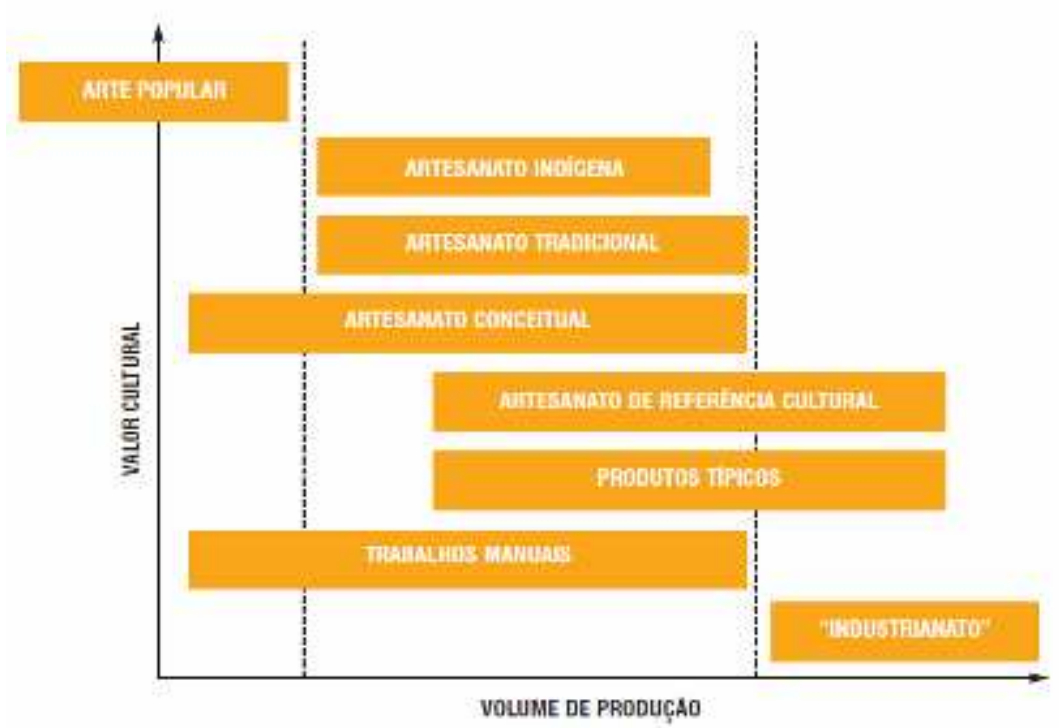

Figura 3 - Critérios para avaliação de tipos de produtos

Fonte: SEBRAE (2004)

Atingir as características de uma linha de artesanato conceitual é o objetivo do projeto. Segundo Barroso Neto $(2000 ; 2001)$, o artesanato conceitual surgiu como alternativa aos produtos industrializados, pregando uma posição ecologicamente mais correta no contexto urbano e contemporâneo. Por este contexto, está ligado à inovação e às tendências, direcionado para um público exigente e às vezes, de médio/alto poder aquisitivo, assim, não está ligado à cultura regional, como o artesanato tradicional.

Para a sobrevivência do artesão no mercado atual, Barroso Neto (2001, p. 40) traz os pilares da infra-estrutura para o trabalho artesanal, "unidades específicas de apoio e execução":

- Núcleo de Inteligência Competitiva para acompanhar as pesquisas de mercado para guiar o desenvolvimento de novos produtos;

- Laboratório de Design para o desenvolvimento de novos produtos, além da identidade, papelaria, embalagens e o acompanhamento dos processos;

- Central de Processamento e Beneficiamento de matéria-prima;

- Núcleo Experimental de Produção;

- Núcleo de Capacitação para a disseminação do conhecimento e das tecnologias

- Cooperativa;

- Central de Comercialização.

Esta abordagem sistêmica, se seguida com organização e empenho, é capaz de colocar o artesanato como uma produção competitiva no mercado globalizado. 
O design pode contribuir compartilhando seus conhecimentos sobre:

- Desenvolvimento de novos produtos;

- Desenvolvimento sustentável;

- Gestão do design;

- Inovação;

- Novos materiais e processos;

- Pesquisa de mercado e tendências.

- E também com:

- Desenvolvimento da identidade visual do negócio;

- Embalagens;

- Mídias de divulgação e comunicação.

O Departamento de Design da UEL tem potencial, e já está usando deste, para transmitir os conhecimentos de técnicas, materiais e processos do design de produtos nas comunidades artesanais. Assim, se estabelece a troca de informações entre o design e a tradição artesanal que culmina em produtos diferenciados, de qualidade e com o cuidado do artigo artesanal, o que pode de chamar de artesanato conceitual. Entretanto, ainda há muito que se fazer neste campo, pois a demanda não é totalmente atendida.

\section{Materiais e Métodos}

\section{A pesquisa-ação}

O método norteador deste trabalho é a pesquisa-ação. (THIOLLENT, 2004).

[...] é um tipo de pesquisa social com base empírica que é concebida e realizada em estreita associação com uma ação ou com um a resolução de um problema coletivo e no qual os pesquisadores e os participantes representativos da situação ou do problema estão envolvidos de modo cooperativo ou participativo. (THIOLLENT, 2004, p.14).

Assim, esta modalidade de pesquisa é considerada dinâmica por contemplar o âmbito da pesquisa científica, com a investigação bibliográfica e a pesquisa social, com o levantamento de dados e a transformação da realidade dos participantes.

O designer de hoje olha para o mercado e para o que está logo ao seu lado na periferia. O feio incomoda. Prefere olhar para si e em um processo de autoreverenciação cria produtos e atividades para os outros designers. É preciso escapar desta zona de conforto e se voltar para os outros $90 \%$. Sem isso não se pode falar em sustentabilidade. Enquanto houver pobreza não haverá sustentabilidade. [...] É preciso urgentemente mudar de estratégia e criar novas soluções. Projetos que envolvam grupos em situação de pobreza exigem a aplicação de estratégias de sustentabilidade inovadoras. (MARTINS; SILVA, 2009, p. 9).

De encontro com o pensamento das autoras Martins e Silva, os objetivos da pesquisa-ação são práticos e imediatos, buscando soluções correspondentes ou, ao menos, "fazer progredir a consciência dos participantes no que diz respeito à existência de soluções e de obstáculos." (MARTINS; SILVA, 2009, p.20). 


\section{O contexto}

\section{Londrina e o setor do vestuário}

Segundo Gomes (2004, p. 4), Londrina "em 70 anos, criou à sua volta uma área de influência de cerca de 4,5 milhões de habitantes num raio de 100 quilômetros, e a Região Metropolitana de Londrina $(\mathrm{RML})^{3}$, foi oficializada com sua inserção no orçamento do Estado do Paraná." Londrina conta com importantes fatores para seu desenvolvimento: sua terra fértil permite até hoje o cultivo de vários produtos agrícolas; sua posição estratégica no Centro-Sul do país que funciona como rota de negócios; sua população jovem e economicamente ativa; e seu sistema de ensino superior, que forma profissionais para abastecer o mercado de trabalho londrinense, além das pesquisas dentro das instituições de ensino, que proporcionam novos produtos e estratégias para o desenvolvimento, econômico, ambiental, social e cultural, da região.

Segundo Vezozzo, Correia e Leite (2004, p. 11), "com o passar dos anos, Londrina adquiriu o perfil de uma região voltada ao setor têxtil, obtendo força devido ao fato de a cidade ser grande produtora de algodão, além de possuir produtores de bicho-da-seda".

O SEBRAE (apud EMÍDIO, 2006, p. 79) estima que existam 435 indústrias do vestuário de moda em Londrina e região.

\begin{tabular}{|l|l|}
\hline Porte da empresa & Número de empresas \\
\hline Microempresa & 282 \\
\hline Empresa de pequeno porte & 101 \\
\hline Empresa de médio porte & 19 \\
\hline Empresa de grande porte & 2 \\
\hline
\end{tabular}

Quadro 1- Distribuição das indústrias do vestuário de moda da região de Londrina por porte Fonte: SEBRAE LONDRINA (apud EMÍDIO, 2006, p. 79)

Entretanto, de acordo com Vezozzo, Correia e Leite (2004) e Emídio (2006), o setor sofre carência de sistemas de gestão (administrativa e de design de moda) para: desenvolver produtos, definir estratégias, orientar o processo, regular o controle de qualidade (em todas as etapas e não apenas a inspeção final, como muitos fazem), aumentar a produtividade e a sua competitividade no mercado nacional.

Implantar sistemas de gestão nas empresas do vestuário é necessário. Em parte delas, o processo já começou a ser introduzido. E é a partir de mudanças de mentalidade, como estas, nas organizações que princípios de sustentabilidade, ou, como mais se tem falado no ambiente dos negócios, responsabilidade social e ambiental, precisam entrar no planejamento.

Para isto, em 2007, foi criado o Arranjo Produtivo Local do Vestuário de Londrina e Região, com "o propósito de integrar as empresas e instituições ligadas à produção de vestuário, promovendo o crescimento do setor." (EMÍDIO; SANCHES, 2009, p. 2). Segundo o Instituto Euvaldo Lodi (2010), o APL do Vestuário de Londrina e Região produz moda jovem,

\footnotetext{
${ }^{3}$ A RML congrega atualmente sete municípios [Londrina, Bela Vista do Paraíso, Cambé, Ibiporã, Jataizinho, Rolândia, Sertanópolis e Tamarana], em torno de 670 mil hab., segundo IBGE, em 2000 (GOMES, 2004, p. 4).
} 
masculina, feminina, gestante, lingerie, moda praia, esportiva, roupas de festa, uniformes, jeans, entre outros.

Dentro do trabalho de conclusão de curso da autora, foram entrevistas confecções do APL do Vestuário de Londrina e região, que hoje, conta com 31 empresas cadastradas na região de Londrina e atuantes em suas ações junto às ações do APL. Destas 31 empresas, cinco responderam sobre o destino de seus resíduos têxteis por e-mail e oito por telefone, totalizando 13 empresas entrevistadas, $42 \%$ delas.

Pode-se observar uma postura positiva das empresas em relação ao destino dos retraços têxteis. Quase todas as entrevistadas, 12 delas, afirmaram se preocupar com o destino dos resíduos, evitando que estes acabem no lixo, prezando por postura social e ecologicamente comprometida com o próximo. Dentre os destinos encontra-se:

a) Reaproveitamento na própria produção: customização das peças (estratégia para a recolocação de peças na venda, a partir daí, peças únicas), flores, colares, tags e detalhes em geral.

b) Doação para pessoas informais: as confecções repassam seus retraços aos catadores de lixo reciclável, produtores de estopa, entre outros que as procurarem pedindo pela doação dos resíduos. Algumas empresas permitem que os funcionários utilizem-se dos resíduos para produzir tapetes, cachecóis e outros produtos artesanais, como um complemento na sua renda. A grande maioria dos informais produz tapetes.

c) Doação para instituições e projetos sociais: Associação de Mulheres, Associação de Costureiras, Casa da Maria, Lar Anália Franco e Bazareco são exemplos de instituições e projetos que recebem os resíduos. Uma das empresas está planejando um projeto social.

Estas empresas fazem parte do APL do Vestuário de Londrina e possuem um grau de instrução e engajamento político e econômico. Todavia, qual a postura das outras dezenas de confecções espalhadas por Londrina e região? Como alcançá-las para transmitir conhecimentos como este? É uma questão a ser tratada dentro do setor, partindo do exemplo das confecções participantes do APL.

Para auxiliar a realização do repasse de resíduos, as empresas podem contar com entidades e instituições, que irão orientá-los, ou mesmo encaminhar diretamente os resíduos aos artesãos que irão utilizá-los. Estas instituições são as Prefeituras, Lares, Casas de Amparo, ONGs, Institutos, como o Milenia, e até os projetos de pesquisa e extensão das. Vale também, ressaltar a importância dos artesãos se associarem. A associação traz visibilidade para o trabalho artesanal e facilita negociações como incentivos e doações.

\section{O projeto IDDS e o artesanato local}

O projeto de pesquisa IDDS vem realizando uma pesquisa de campo com o intuito de conhecer e mapear a produção artesanal local, compreender o cenário socioeconômico, quais os insumos sustentáveis utilizados e principalmente, como micro empreendimentos artesanais podem estar em ciclos produtivos sustentáveis e interconectados a outros, como

\footnotetext{
4 Para o design para sustentabilidade abordar todas as implicações ambientais, econômicas e sociais da concepção de produtos e serviços em todo o seu ciclo de vida, Manzini e Vezzoli (2008, p.23).) desenvolveram a metodologia do Lyfe Cycle Design: "Com a expressão Life Cycle Design entende-se, de fato, uma maneira de conceber o desenvolvimento de novos produtos tendo como objetivos que durante todas as suas fases de projeto, sejam consideradas as possíveis implicações ambientais ligadas às fases do próprio
} 
os ciclos naturais, baseados no conceito do metabolismo industrial. Segundo Polis Estudos (apud CAVALCANTE; NASCIMENTO, 2009, p. 3), "o metabolismo industrial que se fundamenta na conservação da matéria. Baseando-se que a quantidade de matéria que transita na biosfera mantém-se constante, não desaparecendo após o seu descarte apenas perdendo o seu valor econômico." Assim, os resíduos de um ciclo podem, e devem, se tornar insumos de outro para que a matéria seja constante aproveitada.

A região conta com mais de 200 artesãos em Londrina e região, contemplando o artesanato étnico, o artesanato tradicional, os trabalhos manuais e o artesanato de reciclagem.

Os resultados, mesmo que ainda parciais, mostraram as dificuldades do trabalho artesanal - divulgação, comercialização e aquisição de matéria-prima. Para melhorar este quadro, seria útil trazer aos artesãos conhecimentos sobre plano de negócios, controle de qualidade, gestão sustentável, inovação, novos materiais, novos processos e tendências. $E$ trabalhar, junto a eles, comunicação (identidade visual, embalagem, veículos de comunicação), estratégias de marketing e o desenvolvimento de novos produtos.

A questão ambiental abordada na pesquisa mostrou o diminuto conhecimento sobre o assunto, sendo o desenvolvimento sustentável um tópico a ser trabalhado com empenho junto aos artesãos. É necessário integrar à realidade do artesão conhecimentos sobre matérias-primas (natural, renovável e biodegradável), processos de baixo impacto ambiental, análise do ciclo de vida do produto, consumo responsável, uso racional dos recursos naturais e responsabilidade socioambiental.

Todos estes conhecimentos provenientes do design e do desenvolvimento sustentável devem ser incorporados ao saber artesanal para germinar produtos de qualidade, alto valor agregado, para um público diferenciado e consumidor de artesanato.

\section{A contribuição do design}

O design contribui num ciclo de vida do produto artesanal com conhecimentos sobre desenvolvimento de novos produtos, desenvolvimento sustentável; gestão do design; inovação; novos materiais e processos; pesquisa de mercado e tendências, desenvolvimento da identidade visual do negócio, embalagens; mídias de divulgação e comunicação.

O Departamento de Design da UEL tem potencial, e já está usando deste, para transmitir os conhecimentos de técnicas, materiais e processos do design de produtos nas comunidades artesanais. Envolver alunos dos cursos de design gráfico e design de moda enriquece as estratégias do trabalho pela junção de diferentes habilidades. No projeto piloto, em especial, a familiaridade dos alunos de moda com os retraços têxteis e modelagem auxilia no desenvolvimento dos produtos, enquanto a aplicação dos conhecimentos dos alunos do design gráfico é aplicada nas mídias de divulgação, embalagem, identidade visual e na criação dos personagens, os bonecos. E ambos os cursos contribuem na pesquisa de tendências, de mercado e na gestão sustentável do empreendimento.

Assim se estabelece a troca de informações entre o design e a tradição artesanal que culmina em produtos diferenciados, de qualidade e com o cuidado do artigo artesanal, o que pode de chamar de artesanato conceitual. Entretanto, ainda há muito que se fazer neste campo, pois a demanda não é totalmente atendida.

ciclo de vida do produto (pré-produção, produção, distribuição, uso e descarte) buscando, assim, minimizar todos os efeitos negativos possíveis." 


\section{O projeto Empreender do Instituto Milenia}

O projeto é voltado para jovens e adultos que querem aprender um ofício artesanal por meio de cursos e oficinas e gerar renda a partir da sua produção. $O$ foco da produção são os brindes artesanais, tais como canecas, peças decorativas, acessórios, trabalhos em patchwork, camisetas, e principalmente o trabalho com papel reciclado artesanalmente, que produz blocos de anotações, agendas e cadernos. As peças podem ser encomendadas e personalizadas de acordo com a necessidade do cliente. $O$ Instituto oferece suporte para a comercialização dos produtos no próprio instituto, na seda da Milenia, em feiras e exposições.

\section{O projeto piloto}

A Confecção $X^{5}$ fez uma doação de resíduos, entretanto, o instituto recebeu uma encomenda urgente de ecobags e aproveitou a matéria-prima antes que o projeto com o IDDS se estruturasse. A empresa buscou o instituto pela internet e entrou em contato. 0 instituto foi buscar os resíduos, que eram cortinas de provadores descartadas pela mudança de estação, um rolo de jeans e três modelos de bolsas jeans que não emplacaram nas vendas e estavam guardadas. A empresa apenas pediu que as tags e tudo o que identificasse a empresa, fosse retirado para o aproveitamento no instituto. As cortinas de provadores, por terem grandes dimensões, foram utilizadas na produção das ecobags.

Todavia, novos retalhos foram recebidos no instituto, por parte de uma confecção infantil, a Confecção $Y$, e podem ser aproveitados no projeto piloto, além dos ainda restantes resíduos da Confecção $X$.
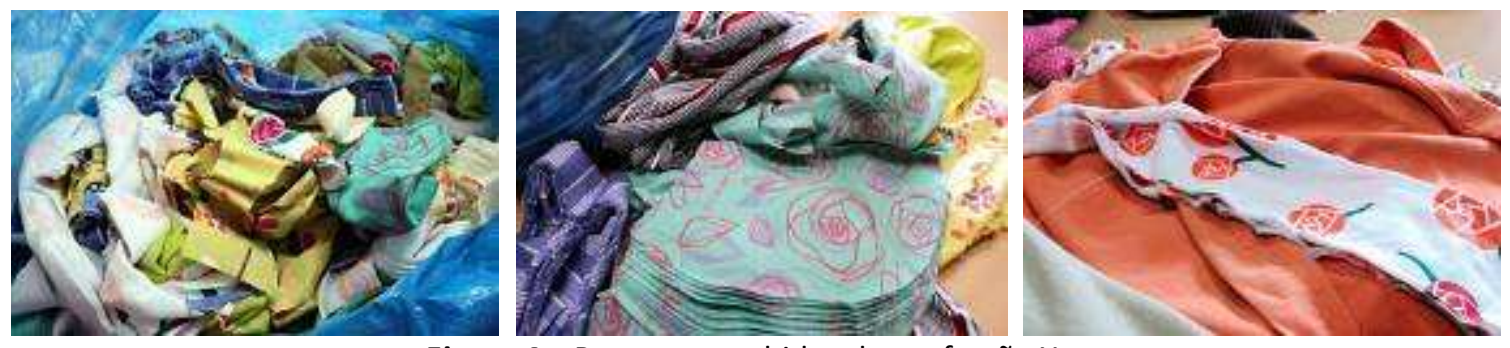

Figura 4 - Retraços recebidos da confecção $Y$

\section{Sensibilização: design e mercado}

Esta primeira etapa consistiu num workshop sobre design e mercado e a apresentação da proposta de novos públicos-alvo para as artesãs. O workshop foi realizado no Instituto Milenia e contou com a presença de 7 artesãs e da coordenadora, Adriana Gonçalves. A seguir, seus principais tópicos:

a) O que é design?

Este tópico apresentou o design, suas funções e competências por meio do dia-a-dia de uma pessoa e o que ela encontra de cultura material como roupas, eletrodomésticos, meios de transporte, eletroeletrônicos, brinquedos, cadernos, revistas, livros e brinquedos.

5 A empresa será tratada como "Confecção X" por questões de sigilo.
6 A empresa será tratada como "Confecção $Y$ " por questões de sigilo. 
b) $O$ artesanato

A partir dos estudos do Programa SEBRAE Artesanato, do SEBRAE (2004), foram apresentadas as características e diferenças do artesanato brasileiro que permitem classificálo em categorias de diferentes valores culturais. Também como realizado o exercício de identificar a categoria da própria produção de acordo com este estudo e discutir cenários futuros, prevendo uma produção conceitual.

c) Artesanato + design

Abordou diferentes casos onde o design agregou novos valores ao artesanato: "Pranchita, recorte de arte e moda", "Mão Gaúcha", "Kre Kygfy, trançado kaingáng", "O Imaginário Pernambucano" e "Moda, Sustentabilidade e Inclusão".

d) Proposta de público alvo

O grupo de pesquisa buscou dois públicos alvo diferentes dos já trabalhados pelo grupo Empreender para dar origem a nova linha: o público infantojuvenil e o feminino.

As características do público infantojuvenil são o gosto pelo trash, o terror divertido, o estranho. 0 público é composto pela criança, o adolescente e o adulto-jovem, de ambos os sexos e de 8 a 25 anos.

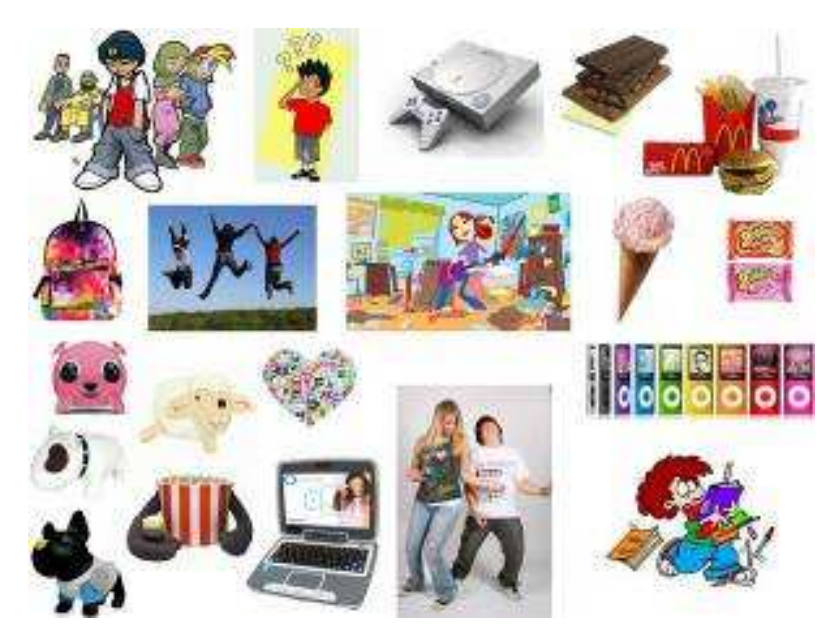

Figura 5 - Painel semântico do público infantojuvenil, composição de Lílian Lago

O público feminino são as mulheres que vivem no meio urbano, agitado, de 25 a 35 anos, possuem família, dividem seu tempo entre a casa e o trabalho, fazem compras, são clientes exigentes e para que toda esta responsabilidade que lhes imposta não torne tudo tão desgastante, buscam objetos divertidos e diferentes para quebrar a rotina.

\footnotetext{
Segundo o dicionário Michaelis do UOL Educação (http://educacao.uol.com.br/dicionarios/), trash significa, na forma de substantivo, rebotalho, pessoa tola ou à toa. E quando verbo, destruir, destroçar, vandalizar.
} 
A linha de produtos consistirá em bonecos trash e suas aplicações, personagens que saem do estereótipo clássico de brinquedos romântico e trazem a irreverência, o humor, a diversão e a presença do estranho. Para expressar estes públicos e mostrar similares dos bonecos, foi feita uma coletânea de exemplos.

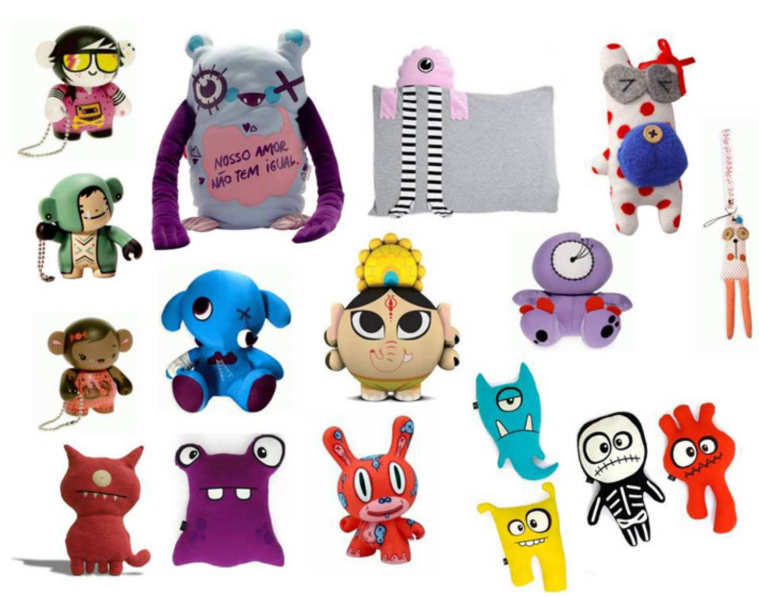

Figura 6 - Exemplos de personagens trash

Os públicos se unem pela possibilidade de serem mães e filhos. A linha de produtos será confeccionada a partir dos resíduos já existentes e com as técnicas que as artesãs dominam.

As artesãs demonstraram grande surpresa quanto a proposta de público, algumas acharam os produtos feios e outras acharam interessantes e, rapidamente, os associaram aos seus filhos e sobrinhos. Enfatizou-se a criação direcionada para um público, não mais a produção de caráter pessoal, típica do artesão. Foi sugerido que as artesãs tragam seus filhos para oficina de criação, assim será possível ter a presença do próprio público durante o projeto.

\section{Caracterização dos resíduos têxteis}

Ao final do workshop, os professores orientaram as artesãs para a classificação dos resíduos para a etapa seguinte, a oficina de criação, duas semanas após o workshop. Foi sugerido como critério de classificação o formato: regular (pequeno, médio e grande), alongado ("tiras") e irregular.

As artesãs classificaram os retraços por formato, tipo de retraço (malha, plush etc) e estampa (lisos; listras; diversos, tais como florais, abstratos etc). Adriana, a responsável pelo instituto entrou em contato com a confecção $Y$ e novamente recebeu retraços da produção infantil, estampas e cores adequadas e interessantes para a confeç̧ão dos produtos. 


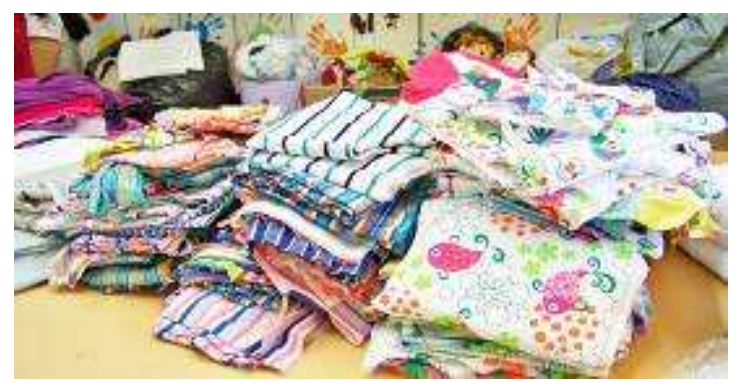

Figura 7 - Retraços classificados pelas artesãs

\section{Geração de ideias}

A geração de ideias se deu em duas etapas: primeiro, a repentina de criação com os alunos de design gráfico e moda na universidade, e depois, a oficina de criação no Instituto Milenia.

A repentina foi realizada durante uma tarde na universidade. Para orientar a criação, os professores sugeriram temas como animais, objetos, bonecos (as) e partes do corpo humano. Todas as criações foram levadas para a oficina de criação no Instituto Milenia e expostas nas paredes para que as artesãs pudessem conhecê-las.

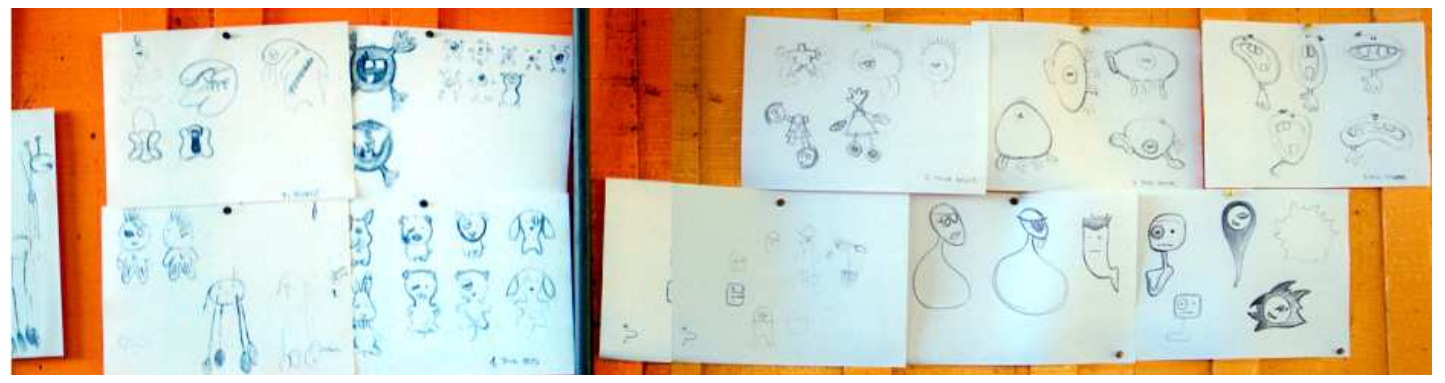

Figura 8 - As gerações de ideias em exposição

$\mathrm{Na}$ oficina de criação, com as criações expostas nas paredes, as artesãs foram convidadas a observá-las, opinar e escolher para produzir as que lhe agradassem.

Tendo os desenhos já escolhidos por elas, deu-se início a etapa de criação dos moldes. Apenas uma das artesãs tinha experiência com confecção de moldes e sabia reproduzir e ampliar os desenhos, então os alunos e professores ajudaram nesta etapa.

Com os moldes já recortados, estes foram utilizados no corte dos tecidos e nos projetos de customização das bolsas.

A costura das peças foi feita tanto nas máquinas de costura do instituto quanto de forma manual, de acordo com o domínio e a preferência da artesã. Para o enchimento, foi utilizada a manta acrílica, já existente no instituto e utilizada em outras peças artesanais produzidas lá. 


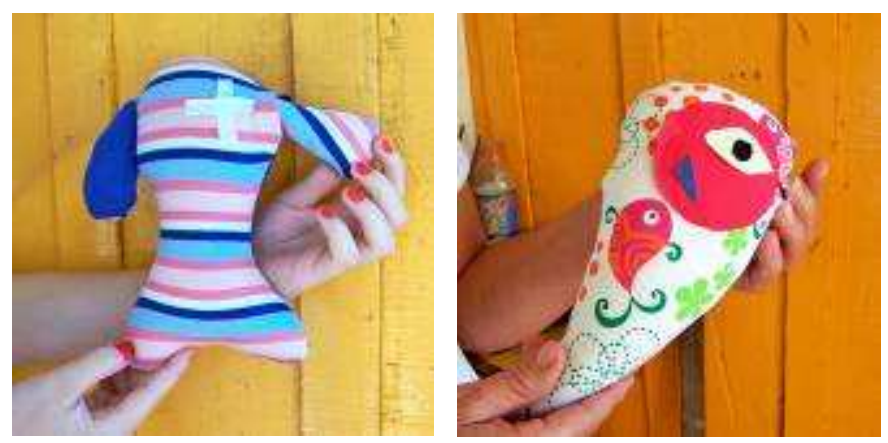

Figura 9 - Peças produzidas na oficina de criação

Os resultados na oficina foram positivos. As artesãs, inicialmente, estranharam a ideia dos produtos trash para o público infantojuvenil, mas, aceitaram o desafio e, durante a criação, passaram a gostar da ideia. Parte deste "afeto" surgido se deve ao fato delas terem participado do processo criativo, escolhendo os desenhos que mais lhe agradaram, os tecidos e cores a serem utilizados, o tamanho da peça e seu processo de produção (manual ou à máquina), caracterizando, assim, uma produção artesanal de fato e não uma interferência externa imposta ao grupo.

\section{Implementação dos produtos}

Durante duas semanas, as artesãs produziram novos protótipos e finalizaram aqueles iniciados na oficina de criação. Este percurso se deu sem a presença da equipe de design para gerir o processo, fato proposital para perceber quais seriam as dificuldades encontradas quando elas estivessem produzindo sozinhas, o que irá acontecer também nas próximas semanas e posteriormente, quando o projeto estiver terminado. A equipe de design se reuniu com as artesãs para analisar os protótipos e detectar as falhas na produção. Os principais problemas encontrados foram:

a) A perda de proporção dos desenhos no risco do molde

As artesãs não possuem um bom domínio das técnicas de desenho, o que prejudicou a transposição do projeto dos bonecos para os moldes maiores. A relação de proporção entre as partes do corpo do boneco foi prejudicada pela inexperiência delas na produção deste estilo de produto.
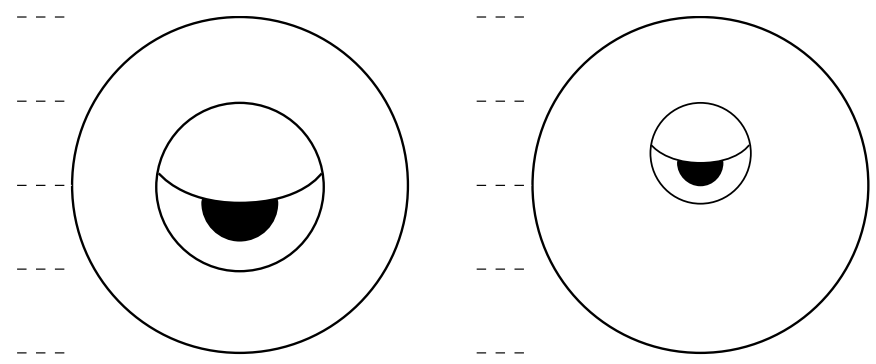

Figura 10 - Um exemplo de diferença entre a proporção proposta pelos desenhos da equipe de design e o molde riscado pelas artesãs

Para entender melhor como preservar estas proporções, a equipe de design explicou por meio da divisão do todo em partes, como visualizar as proporções e utilizá-las no risco do molde. 
b) O uso de cola de tecido

Em algumas peças, foi utilizada a cola de tecido, recurso que não proporcionou um bom aspecto no acabamento, pois o uso da cola ficou evidente e não agregou o valor necessário ao produto.

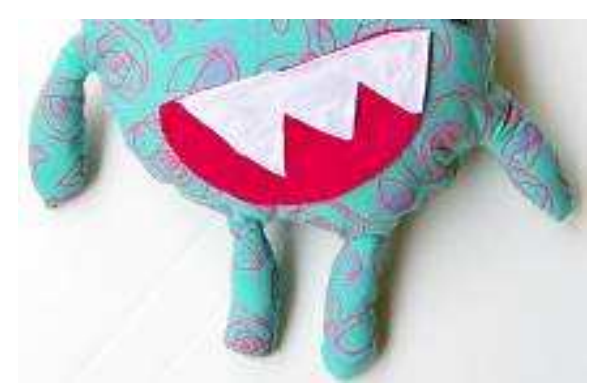

Figura 11 - Peça que recebeu uso de cola para o acabamento

Portanto, determinou-se o não uso de cola e valorização do acabamento em costura, utilizando como exemplo peças neste formato de acabamento, como a costura corrente e o pesponto.

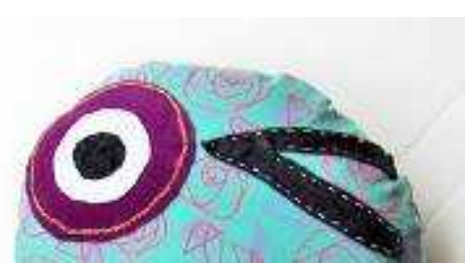

Figura 12 - Peça com aplicações acabadas em costura corrente e pesponto

c) Composição das peças

A composição das peças é uma dificuldade de quase todo o artesão por sua não formação voltada para um pensamento visual, tais como estudos de sintaxe visual e teoria da cor, assim como, pela sua insegurança em utilizar o repertório adquirido com a experiência no trabalho. Uma das peças, por exemplo, utilizava dois tecidos diferentes, mas ambos de listras azuis e verdes.

A artesã relatou ter usado os dois por julgar necessário que a peça contasse com tecidos similares. Porém, os tecidos não harmonizavam na composição pelas tonalidades diferentes das cores e o aspecto marcante das estampas, que buscavam a atenção para si na composição.

Devido à grande quantidade de tecidos estampas de listras e lisos, as artesãs foram orientadas a compor com apenas um tecido, apenas um tecido estampado ou um tecido liso e um estampado, buscando sempre alguma similaridade da cor no par a ser usado.

d) Padronização

Para padronizar a produção, foram estabelecidos três tamanhos de peças baseados nos protótipos já existentes:

- pequenos, de 20 a $30 \mathrm{~cm}$;

- médios, de 30 a $40 \mathrm{~cm}$;

- grandes, de 50 a $70 \mathrm{~cm}$. 
Apenas uma delas não se enquadrava no padrão e será revista na etapa seguinte.

A análise dos protótipos pode revelar um interesse das artesãs em produzir suas peças e a compreensão que elas adquiriram sobre o tema e o público-alvo ao longo das semanas de projeto. As falhas na produção foram detectadas e reconhecidas pelas artesãs, que se comprometeram a atentar-se mais aos detalhes.
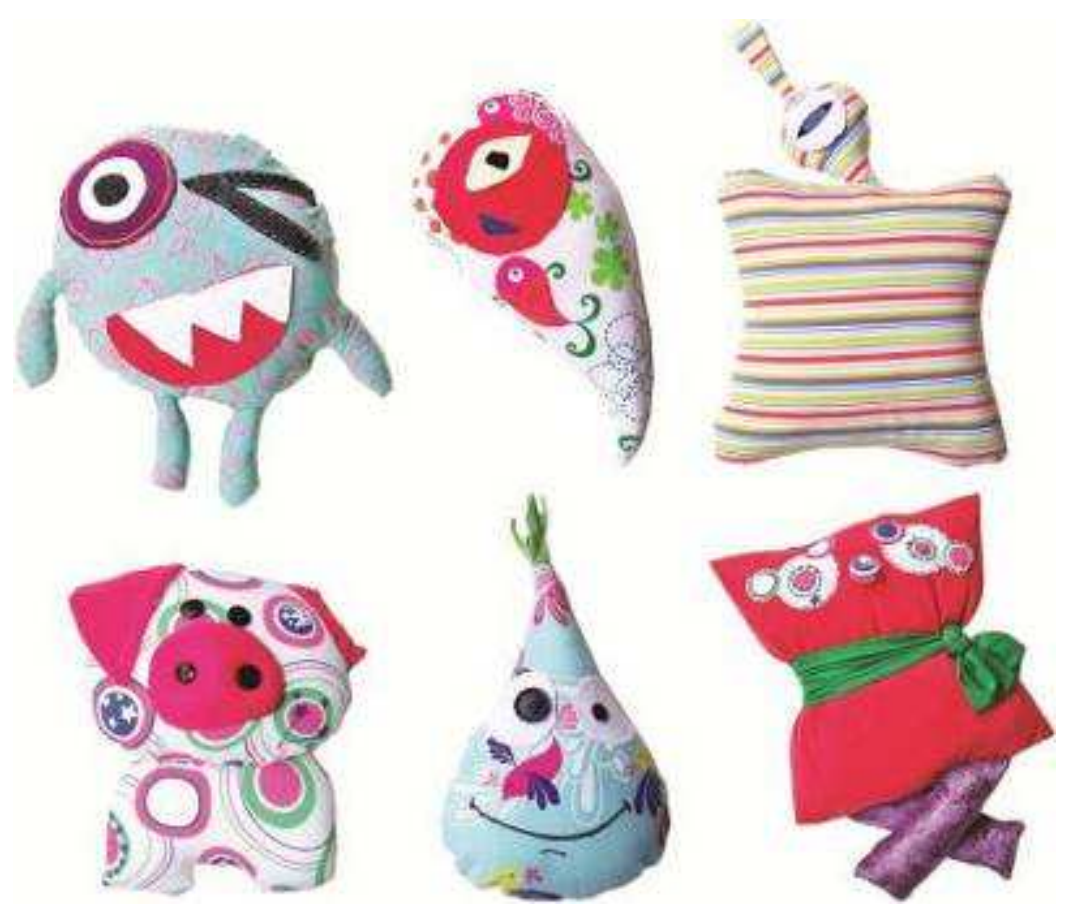

Figura 13- Os primeiros protótipos acabados da produção

A partir destas orientações dadas às artesãs, a produção seguirá e daqui a três semanas, a equipe de design retornará ao instituto para avaliar a produção e fazer os últimos ajustes para a feira que acontecerá na sede da Milenia Agrociências na primeira quinzena de dezembro.

Paralelamente, serão trabalhados o ponto de venda, o uniforme das vendedoras (possivelmente, um avental) e a identidade visual da linha. A equipe de design havia pensado em nomes para a linha de produtos e iria propor Trash 'n crafts, uma brincadeira com o movimento artístico Arts and Crafts. Entretanto, as próprias artesãs passaram a denominar as peças como "Os Esquisitos" e este, provavelmente, será o nome da linha.

Os estudos do ponto de venda móvel já foram iniciados e sua produção partirá do aproveitamento de placas poliondas que a Milenia descarta com frequência. 


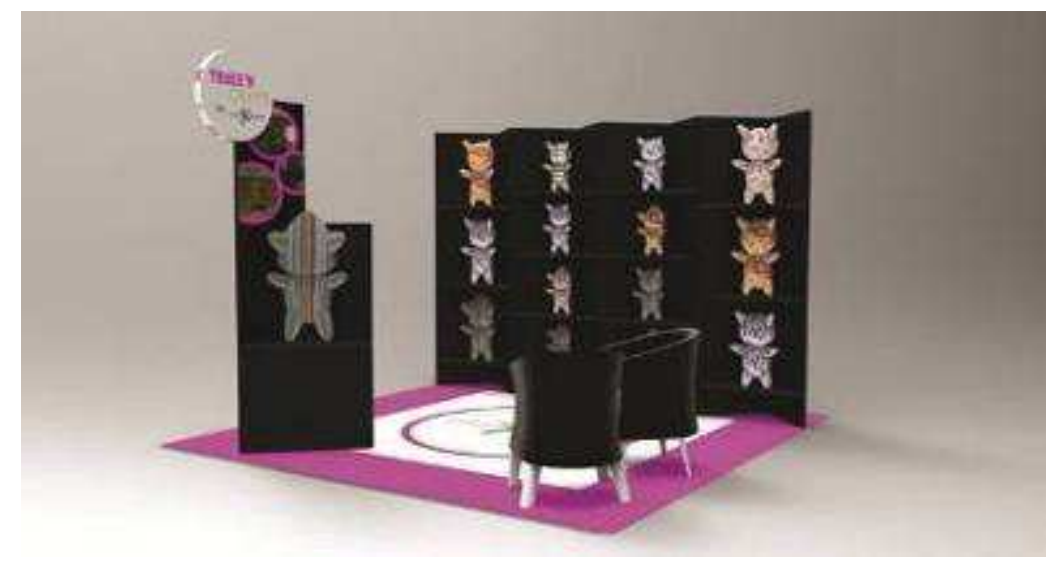

Figura 14 - Proposta de ponto de venda móvel para a linha de produtos

Além do seu ponto de venda móvel, mais a frente, o grupo Empreender irá propor à Confecção $Y$, doadora da maior parte dos retraços utilizados na produção da nova linha, que permita um display de venda dos produtos em uma de suas lojas. Assim, o grupo terá mais um ponto de venda, expondo seus produtos diretamente ao seu público, e a Confecção $Y$ Poderá promover sua responsabilidade socioambiental.

\section{Considerações finais}

A indústria do vestuário, o design (representado pela universidade) e os grupos de geração de renda conseguem trabalhar sob os preceitos do metabolismo industrial, transformando o resíduo industrial em insumo artesanal.

O produto artesanal urbano de hoje, o "industrianato", não possui um alto valor agregado e tem baixa competitividade no mercado. $O$ design entra nesta cadeia produtiva e propõe novos parâmetros: novos públicos, métodos de criação, formas de comunicação e estratégias de mercado, trazendo para os artesãos uma alternativa ao industrianato, o artesanato conceitual.

A indústria precisa se mostrar mais engajada diante da sua comunidade. Iniciativas como as das confecções vistas neste trabalho, devem ser propagadas, e não mais encaradas como filantropia esporádica. Devem ser vistas como estratégias, tanto de comunicação sobre a responsabilidade socioambiental e formação de rede de relacionamentos, como uma destinação correta, e acima de tudo, consciente e limpa, dos seus resíduos.

O artesão, apesar da sua herança cultural de trabalhar muitas vezes sozinho, estando nos centros urbanos, precisa se articular em grupos para obter representatividade e alcançar vantagens. Um artesão teria mais dificuldades em obter contato com uma confecção para receber seus retraços do que uma associação, cooperativa ou grupo, como o Empreender, auxiliado pelo Instituto Milenia, o que thes proporciona ainda melhores condições, como o suporte para a produção, vendas em feiras e divulgação.

Entretanto, o artesão não pode depender desta doação de insumos, pois não há contrato que a regulamente e a intenção é gerar renda e trazer a independência financeira ao artesão. A primeira doação deve ser encarada como talvez a última, e o artesão precisa organizar seus lucros para investir em matéria-prima, caso a doação não se repita.

Por fim, este trabalho mostra que é possível se utilizar dos conhecimentos do design e do desenvolvimento sustentável para, ao mesmo tempo, destinar corretamente os 
retraços têxteis das indústrias do vestuário de Londrina e reaproveitar estes insumos na produção artesanal para a geração de renda.

\section{Referências}

BARROSO NETO, Eduardo. O que é artesanato: módulo 1. 2000. Disponível em: <http:// www.eduardobarroso.com.br/Artesanato_\%20mod1.pdf>. Acesso em: 10 set. 2010.

. Artesanato e mercado. 2001. Disponível em: <http://www.eduardobarroso. com.br/Artesanato_\%20mod2.pdf>. Acesso em: 10 set. 2010.

CAVALCANTE, Ana Luisa B. L. et al. Caracterização do entorno do micro-empreendimento. Londrina: Universidade Estadual de Londrina, 2008. (Projeto de Pesquisa)

CAVALCANTE, Ana Luisa B. L.; PEREIRA, Ana Cláudia do Valle. Artesanato e sustentabilidade: relatos de oficinas de design em microempreendimento solidário. In: SIMPÓSIO BRASILEIRO DE DESIGN SUSTENTÁVEL, 1., 2007, Curitiba. Anais... Curitiba: UFPR, 2007.

CAVALCANTE, Ana Luisa B. L.; NASCIMENTO, Cristianne Cordeiro. Mapeamento de grupos de produção artesanal: um indicador de design para a sustentabilidade. In: SIMPÓSIO BRASILEIRO DE DESIGN SUSTENTÁVEL, 2., 2009, São Paulo. Anais... São Paulo: Universidade Anhembi Morumbi, 2009.

EMÍDIO, Lucimar de Fátima Bilmaia. A gestão de design como ferramenta estratégica para MPE s do vestuário de moda: um estudo de caso na região de Londrina. 2006. Dissertação (Mestrado em Desenho Industrial) - Universidade Estadual Paulista, Bauru, 2006.

EMÍDIO, Lucimar de Fátima Bilmaia; SANCHES, Maria Celeste F. APL do Vestuário de Londrina e Região: uma experiência de gestão integrada do design de moda na cultura organizacional. In: COLÓQUIO DE MODA, 5., 2009, Recife. Anais... Recife: Faculdade Boa Viagem, 2009.

GOMES, Kátia Marcos et al. Caderno Setorial Mercado de Trabalho e Qualificação. 2004. Disponível em: <http://www.codel.londrina.pr.gov.br/geral/geralcadernos.asp>. Acesso: 9 mar. 2010.

KAZAZIAN, Thierry (Org.). Haverá a Idade das Coisas Leves: design e desenvolvimento sustentável. São Paulo: SENAC, 2005.

INSTITUTO EUVALDO LODI. Londrina - Vestuário - APL. Disponível em: <http://www.ielpr.org.br/apl/FreeComponent1574content28064.shtml>. Acesso em: 16 mar. 2010.

LAGO, Lílian. Modelo produtivo sustentável: potencialidades do aproveitamento de retraços têxteis na região de Londrina. 2010. 150 p. Trabalho de Conclusão de Curso (Graduação em Design Gráfico) - Universidade Estadual de Londrina, Londrina, 2010 
MANZINI, Ezio; VEZZOLI, Carlo. Desenvolvimento de Produtos Sustentáveis: os requisitos ambientais dos produtos industriais. São Paulo: Edusp, 2008.

SEBRAE. Programa SEBRAE de Artesanato. 2004. Disponível em:

<http://www.biblioteca.sebrae.com.br/bds/BDS.nsf/83B80234261B3CD683257249004FEBEF /\$File/NT00034A92.pdf>. Acesso em: 10 set. 2010.

SILVA, Bárbara Cravo da. Iniciativas para o desenvolvimento de uma moda sustentável. In: ENCONTRO ANUAL DE INICIAÇÃO CIENTÍFICA, 18., 2009, Londrina. Anais... Londrina: UEL, 2009. p. 12.

THIOLLENT, Michel. Metodologia da pesquisa-ação. 12. ed. São Paulo: Cortez, 2004.

ULLMANN, Christian. Para um design solidário e sustentável. 2007. Disponível em:

<http://www.designemdia.com.br/opiniao/read.php?id=35>. Acesso em: 11 dez. 2009.

VEZOZZO, Charles; CORREIA, Euclides N.; LEITE, Marcos A. Netto. Caderno Setorial Indústria. 2004. Disponível em: <http://www.codel.londrina.pr.gov.br/geral/geralcadernos.asp>. Acesso: 9 mar. 2010. 